\title{
Vascular Endothelial Growth Factor Gene Polymorphism (rs2010963) and Its Receptor, Kinase Insert Domain-Containing Receptor Gene Polymorphism (rs2071559), and Markers of Carotid Atherosclerosis in Patients with Type 2 Diabetes Mellitus
}

\author{
Sebastjan Merlo, ${ }^{1}$ Jovana Nikolajević Starčević, ${ }^{2}$ Sara Mankoč, ${ }^{2}$ Marija Šantl Letonja, ${ }^{3}$ \\ Andreja Cokan Vujkovac, ${ }^{4}$ Marjeta Zorc, ${ }^{2}$ and Daniel Petrovič ${ }^{2}$ \\ ${ }^{1}$ Institute of Oncology Ljubljana, Zaloška 2, Sl-1000 Ljubljana, Slovenia \\ ${ }^{2}$ Institute of Histology and Embryology, Faculty of Medicine, University in Ljubljana, Vrazov trg 2, Sl-1000 Ljubljana, Slovenia \\ ${ }^{3}$ General Hospital Rakičan, Ulica dr. Vrbnjaka 6, Sl-9000 Murska Sobota, Slovenia \\ ${ }^{4}$ General Hospital Slovenj Gradec, Gosposvetska Cesta 1, Sl-2380 Slovenj Gradec, Slovenia
}

Correspondence should be addressed to Daniel Petrovič; dp.petrovic@gmail.com

Received 24 August 2015; Revised 24 October 2015; Accepted 1 November 2015

Academic Editor: Ronald G. Tilton

Copyright (c) 2016 Sebastjan Merlo et al. This is an open access article distributed under the Creative Commons Attribution License, which permits unrestricted use, distribution, and reproduction in any medium, provided the original work is properly cited.

Background. The current study was designed to reveal possible associations between the polymorphisms of the vascular endothelial growth factor (VEGF) gene (rs2010963) and its receptor, kinase insert domain-containing receptor (KDR) gene polymorphism (rs2071559), and markers of carotid atherosclerosis in patients with type 2 diabetes mellitus (T2DM). Patients and Methods. 595 T2DM subjects and 200 control subjects were enrolled. The carotid intima-media thickness (CIMT) and plaque characteristics (presence and structure) were assessed ultrasonographically. Biochemical analyses were performed using standard biochemical methods. Genotyping of VEGF/KDR polymorphisms (rs2010963, rs2071559) was performed using KASPar assays. Results. Genotype distributions and allele frequencies of the VEGF/KDR polymorphisms (rs2010963, rs2071559) were not statistically significantly different between diabetic patients and controls. In our study, we demonstrated an association between the rs 2071559 of KDR and either CIMT or the sum of plaque thickness in subjects with T2DM. We did not, however, demonstrate any association between the tested polymorphism of VEGF (rs2010963) and either CIMT, the sum of plaque thickness, the number of involved segments, hsCRP, the presence of carotid plaques, or the presence of unstable carotid plaques. Conclusions. In the present study, we demonstrated minor effect of the rs2071559 of KDR on markers of carotid atherosclerosis in subjects with T2DM.

\section{Introduction}

Type 2 diabetes mellitus (T2DM) is considered a major epidemic of this century. It is estimated that its prevalence will increase worldwide from 371 million people in 2013 to 552 million people in 2030 [1]. T2DM is associated with accelerated progression of atherosclerosis, the major cause of vascular complications leading to increased morbidity and mortality [2].
Chronic, low-grade inflammation has been demonstrated to be involved in the pathogenesis of atherosclerosis in subjects at high risk to develop cardiovascular disease [37]. Among immune cells infiltrating atherosclerotic lesions, polymorphonuclear neutrophil leukocytes with their products were reported to have an important role in the development and progression of atherosclerosis [8-11]. Marino and coworkers have recently reported that both circulating and intraplaque polymorphonuclear neutrophil leukocytes from 
subjects with carotid atherosclerosis are active producers of different inflammatory mediators including the vascular endothelial growth factor (VEGF) [11].

Several environmental and genetic factors (i.e., hypoxia, hyperglycemia, oxidative stress, ischemia, and gene polymorphisms of VEGF) influence plasma VEGF levels [1216]. Among several polymorphisms of the VEGF gene, the rs2010963 (-634C/G polymorphism of the VEGF gene) and few others were reported to affect serum VEGF levels [1315]. Moreover, rs2010963 was demonstrated to be associated with several disorders, such as diabetic retinopathy, diabetic nephropathy, myocardial infarction, and impaired prognosis in patients with chronic heart failure [13-15, 17]. Despite these findings, however, data about VEGF polymorphisms and their possible association with carotid atherosclerosis in patients with diabetes mellitus are limited [18-20]. Additionally, CIMT is highly heritable and associated with stroke and myocardial infarction, making it a promising quantitative intermediate phenotype for genetic studies of vascular disease [21].

The present study was thus designed to investigate the association between polymorphisms of the VEGF gene (rs2010963) and the KDR gene (rs2071559) and markers of carotid atherosclerosis (such as carotid intima-media thickness (CIMT), the number of affected segments of carotid arteries, and the sum of plaques thickness) in patients with T2DM.

\section{Material and Methods}

The study protocol was approved by the Slovene Medical Ethics Committee in September 2010 (Protocol number 128/09/2010). After an informed consent for the participation in the study was obtained, a detailed interview was made.

This cross-sectional study included 595 subjects with T2DM and 200 subjects without T2DM (control group). They were selected among patients admitted to the diabetes outpatient clinics of the General Hospitals Murska Sobota and Slovenj Gradec, Slovenia. Subjects in the control group were not allowed to have T2DM, and they were the staff of the General Hospital Murska Sobota. Subjects with T2DM and control subjects were excluded if they had homozygous familial hypercholesterolaemia or a previous cardiovascular event such as myocardial infarction or a cerebral stroke.

All ultrasound examinations were performed by two experienced doctors blinded to the participants' diabetes status. The CIMT, defined as the distance from the leading edge of the lumen-intima interface to the leading edge of the media-adventitia interface, was measured, as described previously [22]. Plaques were defined as a focal intima-media thickening and divided into 5 types according to their echogenic/echolucent characteristics, as previously described [22]. The interobserver reliability for carotid plaque characterization was found to be substantial $(\kappa=0.64, p<0.001)$.

The genomic DNA was extracted from $100 \mu \mathrm{L}$ of whole blood using a FlexiGene DNA isolation kit, in accordance with the recommended protocol (Qiagene GmbH, Hilden, Germany).
For VEGF rs2010963 polymorphism competitive allele specific PCR (KASP) was conducted on an ABI Step-One System (Applied Biosystems, Foster City, CA). The reaction mixture $(5 \mu \mathrm{L})$ contained $2.5 \mu \mathrm{L} 2 \mathrm{x}$ KASPar reaction Mix (v3), $0.07 \mu \mathrm{L}$ Assay Mix, $1.43 \mu \mathrm{L}$ of distilled water Dnase/RNasefree (Gibco, Invitrogen Life Technologies), and $10 \mathrm{ng}$ of extracted genomic DNA $(1 \mu \mathrm{L})$. Thermal cycling employed the following conditions: hot-start enzyme activation (15 $\mathrm{min}$ at $94^{\circ} \mathrm{C}$ ), denaturation $\left(20 \mathrm{sec}\right.$ at $\left.94^{\circ} \mathrm{C}\right)$ followed by 10 cycles of touchdown over $65-57^{\circ} \mathrm{C}$ for $60 \mathrm{sec}$ (dropping $0.8^{\circ} \mathrm{C}$ per cycle), and final $26 \mathrm{cycles}$ ( $20 \mathrm{sec}$ at $94^{\circ} \mathrm{C}$ and $60 \mathrm{sec}$ at annealing temperature $57^{\circ} \mathrm{C}$ ). For rs 2071559 (KDR) everything was the same with the exception of thermal conditions. Hot-start enzyme activation $\left(15 \mathrm{~min}\right.$ at $\left.94^{\circ} \mathrm{C}\right)$ and denaturation $(20 \mathrm{sec}$ at $94^{\circ} \mathrm{C}$ ) were followed by 15 cycles of touchdown over $55-$ $65^{\circ} \mathrm{C}$ for $60 \mathrm{sec}$ (dropping $0.8^{\circ} \mathrm{C}$ per cycle) and final 26 cycles $\left(20 \mathrm{sec}\right.$ at $93^{\circ} \mathrm{C}$ and $60 \mathrm{sec}$ at annealing temperature $58^{\circ} \mathrm{C}$ ).

In addition, the fasting serum VEGF levels were analyzed in 70 subjects with T2DM and in 33 subjects with T2DM. For the determination of the fasting serum VEGF concentration (isoform VEGF 165), a solid phase sandwich ELISA using two kinds of high specific antibodies (hVEGF Assay Kit, IBL Co., Ltd. Aramachi, Takasaki-shi, Gunma, Japan) was used. The respective CV (\%) were between 3 and 5.5 for interassay measurements and between 2.6 and 5.3 for intraassay measurements.

Continuous variables are expressed as means \pm standard deviations. Continuous clinical data were compared using unpaired Student's $t$-test or analysis of variance (ANOVA). The Pearson $\chi^{2}$ test was used to compare discrete variables. A two-tailed $p$ value of less than 0.05 was considered statistically significant. A statistical analysis was performed using the SPSS program for Windows version 21 (SPSS Inc., Chicago, Ilinois, USA).

\section{Results}

Patients with T2DM were older, had a greater waist circumference, and had higher fasting glucose and HbAlc levels compared to controls, whereas there were no differences in BMI and systolic and diastolic blood pressure between patients with T2DM and control subjects (Table 1). Patients with T2DM had lower total, HDL, and LDL cholesterol levels and a higher triglyceride level compared to controls (Table 1). Plasma levels of inflammatory markers (i.e., hs-CRP and fibrinogen) were higher in patients with T2DM compared to controls (Table 1). Additionally, there was higher percentage of men, statin therapy, and antihypertensive therapy and lower percentage of smokers in T2DM group compared to control group (Table 1).

The genotype distributions in both patients with T2DM and controls were in Hardy-Weinberg equilibrium for both VEGF gene polymorphisms [rs2010963: T2DM (genotype frequencies: CC genotype $8.7 \%$, CG genotype $47.1 \%$, and GG genotype $44.2 \% ; \chi^{2}=3.48 ; p=0.06$ ) and controls (genotype frequencies: CC genotype $9 \%$, CG genotype $48 \%$, and GG genotype $\left.43 \% ; \chi^{2}=1.46 ; p=0.22\right)$ ]. The genotype distributions in both patients with T2DM and controls 
TABLE 1: Baseline characteristics of subjects with T2DM and subjects without T2DM (control group).

\begin{tabular}{|c|c|c|c|}
\hline & $\begin{array}{c}\text { Subjects with } \\
\text { T2DM } \\
n=595\end{array}$ & $\begin{array}{l}\text { Control } \\
\text { group } \\
n=200\end{array}$ & $p$ \\
\hline Age (years) & $62.39 \pm 9.61$ & $60.07 \pm 9.18$ & 0.008 \\
\hline Male sex (\%) & $338(56.8)$ & $92(46.0)$ & 0.008 \\
\hline $\begin{array}{l}\text { Diabetes duration } \\
\text { (years) }\end{array}$ & $11.25 \pm 7.88$ & - & - \\
\hline $\begin{array}{l}\text { Cigarette smoking } \\
(\%)\end{array}$ & $53(8.91)$ & $34(17.0)$ & 0.002 \\
\hline $\begin{array}{l}\text { Waist circumference } \\
(\mathrm{cm})\end{array}$ & $108.65 \pm 12.88$ & $93.31 \pm 13.18$ & $<0.001$ \\
\hline BMI $\left(\mathrm{kg} / \mathrm{m}^{2}\right)$ & $31.00 \pm 4.74$ & $27.90 \pm 4.42$ & 0.16 \\
\hline SBP (mm Hg) & $147.1 \pm 19.80$ & $143.3 \pm 16.6$ & 0.86 \\
\hline $\mathrm{DBP}(\mathrm{mm} \mathrm{Hg})$ & $85.78 \pm 11.60$ & $84.7 \pm 11.6$ & 0.19 \\
\hline $\begin{array}{l}\text { Fasting glucose } \\
(\mathrm{mmol} / \mathrm{L})\end{array}$ & $8.04 \pm 2.57$ & $5.27 \pm 0.87$ & $<0.001$ \\
\hline HbAlc (\%) & $7.89 \pm 3.56$ & $4.79 \pm 0.29$ & $<0.001$ \\
\hline $\begin{array}{l}\text { Total cholesterol } \\
(\mathrm{mmol} / \mathrm{L})\end{array}$ & $4.70 \pm 1.18$ & $5.36 \pm 1.08$ & $<0.001$ \\
\hline $\begin{array}{l}\text { HDL cholesterol } \\
(\mathrm{mmol} / \mathrm{L})\end{array}$ & $1.20 \pm 0.35$ & $1.43 \pm 0.37$ & $<0.001$ \\
\hline $\begin{array}{l}\text { LDL cholesterol } \\
(\mathrm{mmol} / \mathrm{L})\end{array}$ & $2.63 \pm 0.94$ & $3.24 \pm 0.98$ & $<0.001$ \\
\hline $\begin{array}{l}\text { Triglycerides } \\
(\mathrm{mmol} / \mathrm{L})\end{array}$ & $1.9(1.2-2.7)$ & $1.3(0.9-1.9)$ & $<0.001$ \\
\hline hs-CRP (mg/L) & $3.5 \pm 1.18$ & $2.2 \pm 1.18$ & $<0.001$ \\
\hline CIMT $(\mu \mathrm{m})$ & $958 \pm 194$ & $890 \pm 212$ & 0.007 \\
\hline Statin therapy (\%) & $375(63.0)$ & $62(31.0)$ & $<0.001$ \\
\hline $\begin{array}{l}\text { Antihypertensive } \\
\text { agents (\%) }\end{array}$ & 499 (83.9) & $58(29 \%)$ & $<0.001$ \\
\hline
\end{tabular}

Continuous variables were expressed as means \pm standard deviations when normally distributed and as median (interquartile range) when asymmetrically distributed. Categorical variables were expressed as frequency (percentage). BMI: body mass index; SBP: systolic blood pressure; DBP: diastolic blood pressure; HbAlc: glycated haemoglobin; hs-CRP: high sensitivity Creactive protein.

were in Hardy-Weinberg equilibrium for the KDR gene polymorphism [rs2071559: T2DM (genotype frequencies: CC genotype $22.0 \%$, CT genotype $51.9 \%$, and TT genotype $26.1 \%$; $\chi^{2}=0.97 ; p=0.33$ ) and controls (genotype frequencies: CC genotype $30.0 \%$, CT genotype $48.0 \%$, and TT genotype $\left.22.0 \% ; \chi^{2}=0.63 ; p=0.23\right)$ ]. No statistically significant differences in the VEGF rs2010963 and KDR rs2071559 genotype distribution frequencies were observed between T2DM patients and controls.

The observed minor allele frequency (MAF) distributions were mostly in agreement with the 1000 Genomes Project data in the European population. The $\mathrm{C}$ allele frequency of the VEGF rs2010963 showed no significant difference $(p=0.79)$ between patients with T2DM and controls $(32.3 \%$ versus $33 \%)$. However, the $\mathrm{C}$ allele frequency of the KDR rs2071559 polymorphism was significantly lower $(p=0.04)$ in T2DM subjects as compared to the controls ( $49 \%$ versus $54 \%$ ).
Higher VEGF serum levels were demonstrated in subjects with T2DM with the CC genotype (rs2010963) compared to those with other $(C G+G G)$ genotypes (Table 2). Moreover, higher VEGF serum levels were found in subjects with the CC genotype (rs2071559) compared to those with other (CT + TT) genotypes (Table 2).

The comparison of atherosclerosis parameters was performed with regard to different genotypes of the VEGF polymorphism (rs2010963) upon enrolment. In our study, we did not demonstrate any association between the rs 2010963 and either CIMT, the sum of plaque thickness, the number of involved segments, hsCRP or the presence of carotid plaques, or the presence of unstable carotid plaques (Tables 3 and 4). We did, however, demonstrate an association between the rs2071559 and either CIMT or the sum of plaque thickness in subjects with T2DM (Table 3).

\section{Discussion}

In our study, we demonstrated an association between the rs2071559 of KDR and CIMT in subjects with T2DM, whereas we did not demonstrate an association between tested polymorphism of VEGF (rs2010963) and CIMT. Variations in the VEGF gene were reported to be weakly associated with CIMT [19]. None of the single genotyped polymorphisms $(-2578 \mathrm{~A}>\mathrm{C}$ rs699947, $-634 \mathrm{C}>\mathrm{G}$ rs2010963, and $+936 \mathrm{C}>\mathrm{T}$ rs3025039) were significantly associated with overall IMT in the study reported by Kangas-Kontio and coworkers [19]. The haplotype CCC, however, was associated with higher overall CIMT in women and the haplotype CCT with higher CIMT in the internal carotid artery in men [19].

Additionally, we also demonstrated an association between the rs2071559 of KDR and the sum of plaque thickness in subjects with T2DM, whereas no association between tested polymorphism of VEGF (rs2010963) and markers of carotid atherosclerosis was demonstrated. The rs2010963 polymorphism of the VEGF gene was not demonstrated to exert a significant influence on the risk of subclinical atherosclerosis manifested by the presence of endothelial dysfunction by brachial artery reactivity and increased CIMT in a series of patients with rheumatoid arthritis [23]. Contrary, the importance of VEGF and its receptor (VEGFR1) was reported by Russell and coworkers [24]. They analyzed 34 intact carotid endarterectomy specimens and compared histologically stable and unstable plaques. In unstable plaques (cap rupture/thinning) increased VEGF and receptor (VEGFR1) staining as well as increased microvessel density was demonstrated in comparison with stable carotid plaques [24]. Additionally, Marino and coworkers have recently reported that both circulating and intraplaque polymorphonuclear neutrophils (PMN) from subjects with carotid atherosclerosis are active producers of VEGF, IL-8, and elastase [11]. Moreover, an evidence is provided that these PMN have an increased ability to produce VEGF (at mRNA levels) in comparison to cells from healthy subjects. Additionally, increased VEGF mRNA occurs in both intraplaque and circulating PMN, at rest as well as after stimulation, suggesting that such functional 
TABLE 2: VEGF serum levels in subjects with and without T2DM with regard to the rs2010963 and rs2071559 genotypes.

\begin{tabular}{|c|c|c|c|c|c|}
\hline \multirow{2}{*}{ rs2010963 } & \multicolumn{2}{|c|}{ Mean $(95 \%$ CI $)$} & \multirow{2}{*}{$p$} & \multicolumn{2}{|c|}{ Linear trend analysis } \\
\hline & CC (52) & $\mathrm{CG}+\mathrm{GG}(543)$ & & $F$ & $p$ \\
\hline VEGF (ng/L) & $63.5 \pm 29.2$ & $46.1 \pm 22.3$ & $<0.01$ & 3.22 & 0.03 \\
\hline \multirow{2}{*}{ rs2071559 } & \multicolumn{2}{|c|}{ Mean $(95 \%$ CI $)$} & \multirow[b]{2}{*}{$p$} & \multicolumn{2}{|c|}{ Linear trend analysis } \\
\hline & CC (131) & $\mathrm{CT}+\mathrm{TT}(464)$ & & $F$ & $p$ \\
\hline VEGF (ng/L) & $69.4 \pm 25.1$ & $40.9 \pm 28.3$ & $<0.01$ & 3.70 & 0.02 \\
\hline
\end{tabular}

TABLE 3: Comparison of markers of carotid atherosclerosis (CIMT, sum of plaque thickness, and number of involved segments) in subjects with T2DM at the beginning of the study with regard to the rs2010963 and rs2071559 genotypes.

\begin{tabular}{|c|c|c|c|c|c|c|}
\hline \multirow{2}{*}{ rs2010963 } & \multicolumn{3}{|c|}{ Mean $(95 \%$ CI $)$} & \multirow{2}{*}{$p$} & \multicolumn{2}{|c|}{ Linear trend analysis } \\
\hline & CC (52) & CG $(280)$ & GG (263) & & $F$ & $p$ \\
\hline CIMT $(\mu \mathrm{m})$ & $\begin{array}{l}1045 \pm 192 \\
(969-1121)\end{array}$ & $\begin{array}{c}996 \pm 210 \\
(964-1026)\end{array}$ & $\begin{array}{l}1026 \pm 210 \\
(995-1058)\end{array}$ & 0.27 & 2.29 & 0.13 \\
\hline Sum of plaque thickness (mm) & $\begin{array}{c}7.58 \pm 4.52 \\
(5.67-9.49)\end{array}$ & $\begin{array}{l}7.79 \pm 4.28 \\
(7.09-8.48)\end{array}$ & $\begin{array}{l}8.11 \pm 4.73 \\
(7.35-8.88)\end{array}$ & 0.76 & 0.009 & 0.93 \\
\hline Number of involved segments & $\begin{array}{c}2.67 \pm 1.51 \\
(2.07-3.26) \\
\end{array}$ & $\begin{array}{l}2.48 \pm 1.70 \\
(2.24-2.73)\end{array}$ & $\begin{array}{l}2.54 \pm 1.60 \\
(2.31-2.77)\end{array}$ & 0.84 & 0.34 & 0.56 \\
\hline \multirow{2}{*}{ rs2071559 } & \multicolumn{3}{|c|}{ Mean $(95 \%$ CI $)$} & \multicolumn{3}{|c|}{ Linear trend analysis } \\
\hline & CC (131) & TC (309) & TT (155) & $P$ & $F$ & $p$ \\
\hline CIMT $(\mu \mathrm{m})$ & $\begin{array}{c}1053 \pm 186 \\
(1012-1092)\end{array}$ & $\begin{array}{l}1029 \pm 200 \\
(987-1070)\end{array}$ & $\begin{array}{c}988 \pm 219 \\
(958-1019)\end{array}$ & 0.04 & 5.64 & 0.04 \\
\hline Sum of plaque thickness (mm) & $\begin{array}{l}8.81 \pm 4.30 \\
(7.83-9.78)\end{array}$ & $\begin{array}{l}8.27 \pm 4.50 \\
(7.26-9.29)\end{array}$ & $\begin{array}{l}7.31 \pm 4.48 \\
(6.61-8.00)\end{array}$ & 0.03 & 5.91 & 0.02 \\
\hline Number of involved segments & $\begin{array}{c}2.87 \pm 1.41 \\
(0.94-1.65) \\
\end{array}$ & $\begin{array}{l}2.38 \pm 1.60 \\
(0.95-1.73) \\
\end{array}$ & $\begin{array}{c}2.24 \pm 1.70 \\
(0.98-1.46) \\
\end{array}$ & 0.64 & 0.22 & 0.83 \\
\hline
\end{tabular}

TABLE 4: Comparison of markers of carotid atherosclerosis (presence of carotid plaques, presence of unstable plaques) in subjects with T2DM at the beginning of the study with regard to the rs2010963 and rs2071559 genotypes.

\begin{tabular}{|c|c|c|c|c|c|c|c|c|}
\hline & \multicolumn{4}{|c|}{ rs2010963 } & \multicolumn{4}{|c|}{ rs2071559 } \\
\hline & CC (52) & CG (280) & GG (263) & $p$ & CC (131) & TC (309) & TT (155) & $p$ \\
\hline $\begin{array}{l}\text { Presence of carotid plaques } \\
n(\%)\end{array}$ & $46(88.5)$ & $229(81.8)$ & $223(84.7)$ & & $117(89.3)$ & $250(80.9)$ & $133(85.8)$ & \\
\hline OR (95\% CI) & $*$ & $\begin{array}{c}0.68 \\
(0.46-2.57)\end{array}$ & $\begin{array}{c}0.72 \\
(0.41-1.26)\end{array}$ & 0.45 & $*$ & $\begin{array}{c}0.57 \\
(0.53-2.06)\end{array}$ & $\begin{array}{c}0.68 \\
(0.34-1.34)\end{array}$ & 0.15 \\
\hline$p^{\dagger}$ & - & 0.70 & 0.24 & & - & 0.59 & 0.26 & \\
\hline $\begin{array}{l}\text { Presence of unstable } \\
\text { carotid plaques } n(\%)\end{array}$ & 27 (51.9) & $143(51.1)$ & $121(46.0)$ & & $69(52.7)$ & $142(46.0)$ & 77 (49.7) & \\
\hline OR (95\% CI) & $*$ & $\begin{array}{c}1.09 \\
(0.22-3.66)\end{array}$ & $\begin{array}{c}0.97 \\
(0.38-2.50)\end{array}$ & 0.45 & * & $\begin{array}{c}0.55 \\
(0.14-2.18)\end{array}$ & $\begin{array}{c}0.67 \\
(0.20-2.26)\end{array}$ & 0.42 \\
\hline$p^{\dagger}$ & - & 0.56 & 0.59 & & - & 0.39 & 0.51 & \\
\hline
\end{tabular}

${ }^{*}$ Reference genotype is CC.

${ }^{\dagger} p$ value for logistic regression analysis.

changes are systemic and not limited to cells infiltrating the vascular wall [11]. In contrast to these findings, we did not demonstrate an effect of VEGF/KDR polymorphisms on the presence of either plaques or unstable plaques, since no difference in genotype distribution was present.

In our study, the effect of either rs2071559 of KDR or rs2010963 on VEGF serum levels was demonstrated. These findings are in accordance with our previous studies in which subjects with recent MI history (up to 9 months after MI) were enrolled $[13,16,25]$. Moreover, increased plasma VEGF levels demonstrated in the stable phase after MI correlated with inflammation cytokines (IL-8 and IL-6), but not with atherosclerotic burden [25].

In contrast to the minor effect of the rs2071559 of KDR and the absence of the rs2010963 of the VEGF, an association of either rs2071559 or rs2010963 with MI has recently been 
reported in Caucasians with T2DM [13, 16, 24]. Our present findings and previous reports are additional evidence that markers of carotid atherosclerosis and atherothrombotic events (i.e., MI) are most probably not regulated via similar genetical/biological mechanisms.

To conclude, in our study we demonstrated a minor effect of the rs2071559 of KDR on markers of carotid atherosclerosis (CIMT, sum of plaque thickness) in subjects with T2DM, whereas we failed to demonstrate an effect of tested polymorphism of the VEGF gene (rs2010963) on markers of carotid atherosclerosis.

\section{Conflict of Interests}

The authors declare that there is no conflict of interests regarding the publication of this paper.

\section{Acknowledgment}

The authors thank Mrs. Brina Beškovnik, BA, for revising the English.

\section{References}

[1] M. Laakso and J. Kuusisto, "Insulin resistance and hyperglycaemia in cardiovascular disease development," Nature Reviews Endocrinology, vol. 10, no. 5, pp. 293-302, 2014.

[2] P. R. Moreno and V. Fuster, "New aspects in the pathogenesis of diabetic atherothrombosis," Journal of the American College of Cardiology, vol. 44, no. 12, pp. 2293-2300, 2004.

[3] L. Guasti, F. Marino, M. Cosentino et al., "Simvastatin treatment modifies polymorphonuclear leukocyte function in high-risk individuals: a longitudinal study," Journal of Hypertension, vol. 24, no. 12, pp. 2423-2430, 2006.

[4] F. Marino, L. Guasti, M. Cosentino et al., "Angiotensin II type 1 receptor expression in polymorphonuclear leukocytes from high-risk subjects: changes after treatment with simvastatin," Journal of Cardiovascular Pharmacology, vol. 49, no. 5, pp. 299305, 2007.

[5] L. Guasti, F. Marino, M. Cosentino et al., "Prolonged statinassociated reduction in neutrophil reactive oxygen species and angiotensin II type 1 receptor expression: 1-year follow-up," European Heart Journal, vol. 29, no. 9, pp. 1118-1126, 2008.

[6] N. Khuseyinova and W. Koenig, "Biomarkers of outcome from cardiovascular disease," Current Opinion in Critical Care, vol. 12, no. 5, pp. 412-419, 2006.

[7] P. N. Hopkins, "Molecular biology of atherosclerosis," Physiological Reviews, vol. 93, no. 3, pp. 1317-1542, 2013.

[8] A. Mócsai, "Diverse novel functions of neutrophils in immunity, inflammation, and beyond," The Journal of Experimental Medicine, vol. 210, no. 7, pp. 1283-1299, 2013.

[9] R. Baetta and A. Corsini, "Role of polymorphonuclear neutrophils in atherosclerosis: current state and future perspectives," Atherosclerosis, vol. 210, no. 1, pp. 1-13, 2010.

[10] M. Van Leeuwen, M. J. J. Gijbels, A. Duijvestijn et al., "Accumulation of myeloperoxidase-positive neutrophils in atherosclerotic lesions in $\mathrm{LDLR}^{-1-}$ mice," Arteriosclerosis, Thrombosis, and Vascular Biology, vol. 28, no. 1, pp. 84-89, 2008.

[11] F. Marino, M. Tozzi, L. Schembri et al., "Production of IL-8, VEGF and elastase by circulating and intraplaque neutrophils in patients with carotid atherosclerosis," PLoS ONE, vol. 10, no. 4, Article ID e0124565, 2015.

[12] T. Awata, K. Inoue, S. Kurihara et al., "A common polymorphism in the $5^{\prime}$-untranslated region of the VEGF gene is associated with diabetic retinopathy in type 2 diabetes," Diabetes, vol. 51, no. 5, pp. 1635-1639, 2002.

[13] D. Petrovič, R. Verhovec, M. Globočnik Petrovič, J. Osredkar, and B. Peterlin, "Association of vascular endothelial growth factor gene polymorphism with myocardial infarction in patients with type 2 diabetes," Cardiology, vol. 107, no. 4, pp. 291-295, 2007.

[14] M. G. Petrovič, P. Korošec, M. Košnik et al., "Local and genetic determinants of vascular endothelial growth factor expression in advanced proliferative diabetic retinopathy," Molecular Vision, vol. 14, pp. 1382-1387, 2008.

[15] P. van der Meer, R. A. de Boer, H. L. White et al., "The VEGF +405 CC promoter polymorphism is associated with an impaired prognosis in patients with chronic heart failure: a MERIT-HF substudy," Journal of Cardiac Failure, vol. 11, no. 4, pp. 279-284, 2005.

[16] S. Kariž and D. Petrovič, "Minor association of kinase insert domain-containing receptor gene polymorphism (rs2071559) with myocardial infarction in Caucasians with type 2 diabetes mellitus: case-control cross-sectional study," Clinical Biochemistry, vol. 47, no. 16-17, pp. 192-196, 2014.

[17] P. Douvaras, D. G. Antonatos, K. Kekou et al., "Association of VEGF gene polymorphisms with the development of heart failure in patients after myocardial infarction," Cardiology, vol. 114, no. 1, pp. 11-18, 2009.

[18] E. Alioglu, U. Turk, S. Cam, A. Abbasaliyev, I. Tengiz, and E. Ercan, "Polymorphisms of the methylenetetrahydrofolate reductase, vascular endothelial growth factor, endothelial nitric oxide synthase, monocyte chemoattractant protein-1 and apolipoprotein E genes are not associated with carotid intimamedia thickness," Canadian Journal of Cardiology, vol. 25, no. 1, pp. el-e5, 2009.

[19] T. Kangas-Kontio, J. M. Tapanainen, H. Huikuri et al., "Variation in the vascular endothelial growth factor gene, carotid intima-media thickness and the risk of acute myocardial infarction," Scandinavian Journal of Clinical and Laboratory Investigation, vol. 69, no. 3, pp. 335-343, 2009.

[20] C. Giannarelli, M. Alique, D. T. Rodriguez et al., "Alternatively spliced tissue factor promotes plaque angiogenesis through the activation of HIF- $1 \alpha$ and VEGF signaling," Circulation, vol. 130, pp. 1274-1286, 2014.

[21] L. Paternoster, N. A. Martinez-Gonzalez, R. Charleton, M. Chung, S. Lewis, and C. L. M. Sudlow, "Genetic effects on carotid intima-media thickness: systematic assessment and meta-analyses of candidate gene polymorphisms studied in more than 5000 subjects," Circulation: Cardiovascular Genetics, vol. 3, no. 1, pp. 15-21, 2010.

[22] J. Nikolajevic Starcevic, M. Santl Letonja, Z. J. Praznikar, J. Makuc, A. C. Vujkovac, and D. Petrovic, "Polymorphisms XbaI (rs693) and EcoRI (rs1042031) of the ApoB gene are associated with carotid plaques but not with carotid intima-media thickness in patients with diabetes mellitus type 2," Vasa, vol. 43, no. 3, pp. 171-180, 2014.

[23] L. Rodríguez-Rodríguez, M. García-Bermúdez, C. GonzálezJuanatey et al., "Vascular endothelial growth factor A and cardiovascular disease in rheumatoid arthritis patients," Tissue Antigens, vol. 77, no. 4, pp. 291-297, 2011. 
[24] D. A. Russell, C. R. Abbott, and M. J. Gough, "Vascular endothelial growth factor is associated with histological instability of carotid plaques," British Journal of Surgery, vol. 95, no. 5, pp. 576-581, 2008.

[25] B. Eržen, M. Šilar, and M. Šabovič, "Stable phase post-MI patients have elevated VEGF levels correlated with inflammation markers, but not with atherosclerotic burden," BMC Cardiovascular Disorders, vol. 14, no. 1, pp. 166-170, 2014. 


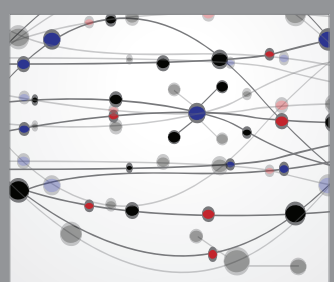

The Scientific World Journal
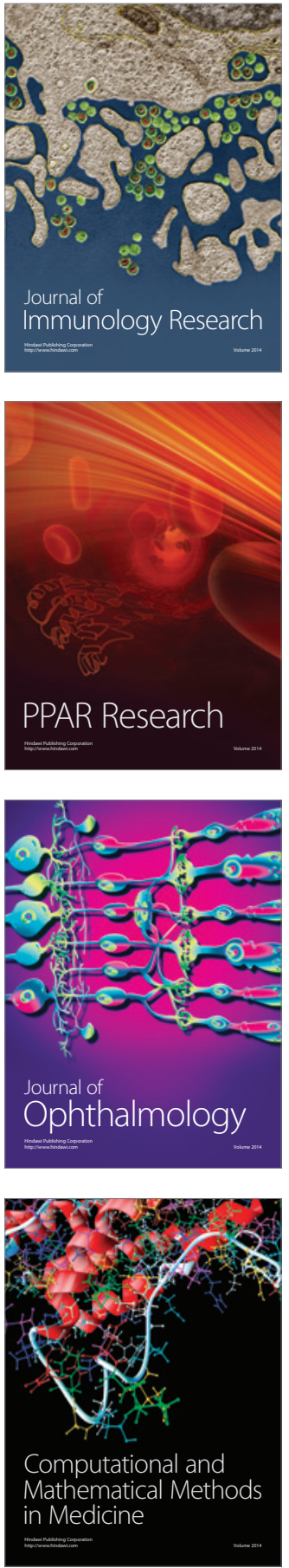

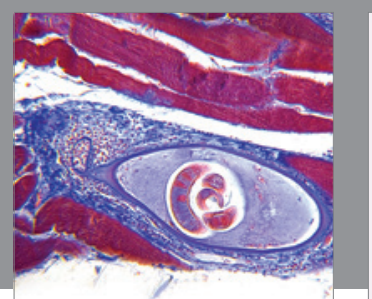

Gastroenterology Research and Practice

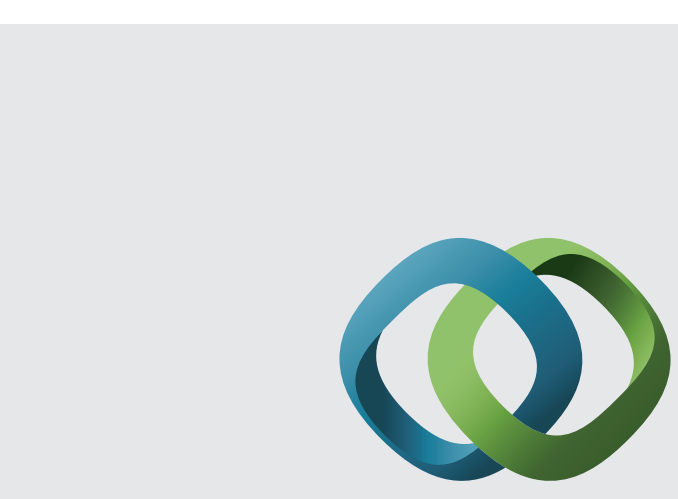

\section{Hindawi}

Submit your manuscripts at

http://www.hindawi.com
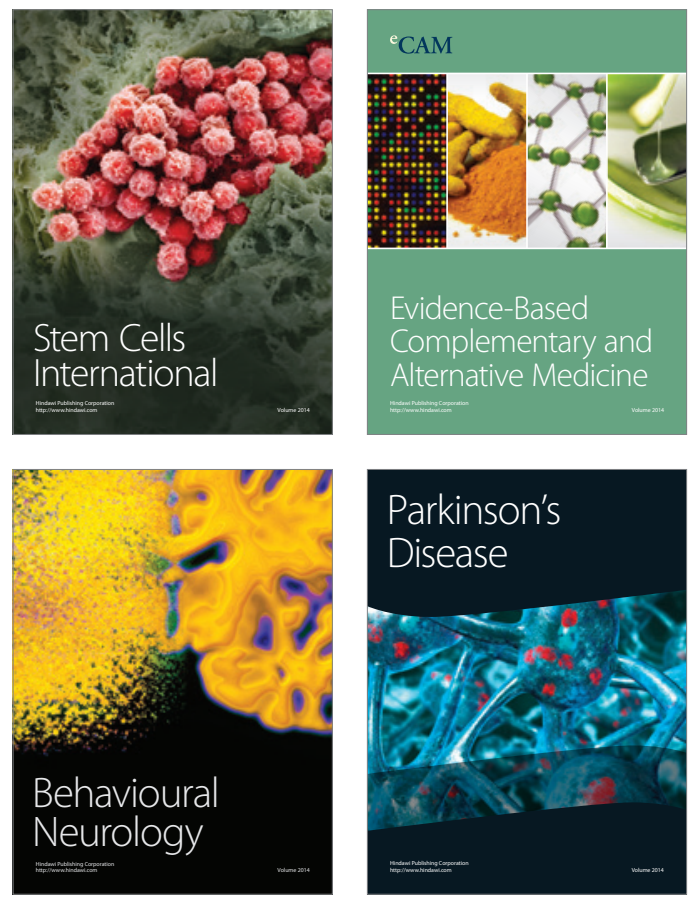
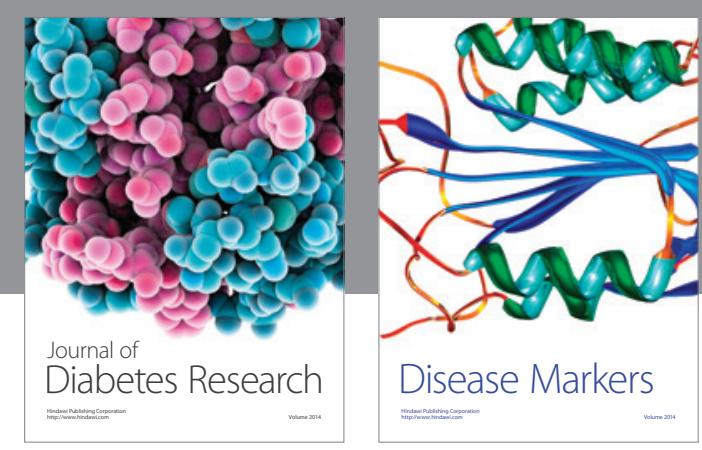

Disease Markers
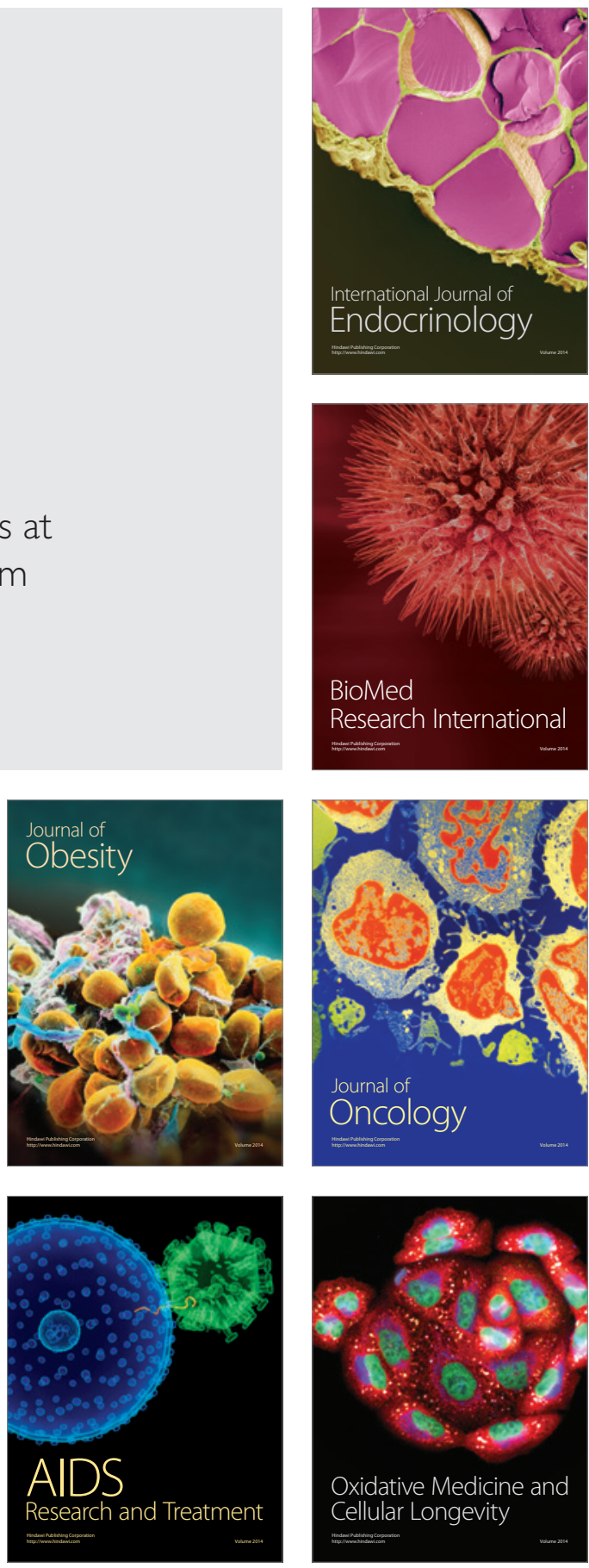